\title{
A Presença de Deus no Ser Humano segundo Heschel
}

\section{God's Presence before Humans according to Heschel}

\author{
Maria Gloria Hazan ${ }^{1}$ \\ Luiz Felipe Pondé
}

\begin{abstract}
Deus me persegue em toda parte, como um tremor O desejo em mim é por descanso; ele me convocando diz: vem! Percebo visões vagando como mendigos pela ruas!

Eu vou com meus devaneios

Como num corredor através do mundo, Às vezes, vejo suspensa em mim a face sem face de Deus. ${ }^{3}$
\end{abstract}

\begin{abstract}
Resumo: O artigo explora a relação do ser humano com o inefável e quais os caminhos para a presença de Deus na consciência religiosa, de acordo com Abraham Heschel, através da visão bíblica de mundo, nas seguintes categorias: sublime, maravilhoso, mistério, temor e glória. O resgate desses sentimentos dentro da religião é fundamental para a experiência da fé.
\end{abstract}

Palavras-Chave: atitude religiosa, Heschel, natureza, oração, temporalidade.

\begin{abstract}
The article explores the relation of the human being to the ineffable and the ways into the presence of God in religious consciousness, according to Abraham Heschel, through the Biblical view of the world, in the following categories: sublime, wonder, mystery, awe and glory . The recovery of these feelings within religion is fundamental to the experience of faith.

Keywords: religious attitude, Heschel, nature, prayer, temporality.
\end{abstract}

\footnotetext{
${ }^{1}$ PUC-SP < gueula@me.com >

${ }^{2}$ PUC-SP < ponde.folha@uol.com.br>

${ }^{3}$ Abraham Joshua HESCHEL apud Alexandre LEONE, A imagem divina e o pó da terra. São Paulo: Humanitas-FFLCH/USP-FAPESP, 2002, p. 69-70.
} 


\section{1 - Heschel e a questão do tempo}

Para iniciar esta reflexão, precisamos entender como Abraham Heschel aborda e prioriza a qualidade do tempo em relação à conquista do espaço. O autor diz que a preocupação do homem moderno é principalmente com o domínio do espaço. Já a questão do tempo, para ele PUC-SP, deve ser abordada em dois aspectos, de temporalidade e de eternidade, para compreender que "o permanente não começa além, mas sim, dentro do tempo, dentro do momento, dentro do concreto" 4 .

A partir desta abordagem, podemos compreender o significado do sétimo dia e a prioridade de sua observância para a piedade judaica. O dia do Schabat encontra, por meio do ritual, a presença da santidade como possibilidade exclusiva do homem, além de ser um dia de suma importância na tradição judaica, tanto como significado da religiosidade aplicada ao tempo existencial, como fundamental para o exercício das mitzvot (mandamentos), que representam os instrumentos que viabilizam desenvolver as virtudes e alcançar o amor. Heschel baseia-se no fato da premissa religiosa estar implícita na condição humana como possibilidade de transcendência, ou seja, o homem é capaz de se elevar no sentido do divino, além das perspectivas do ego.

O autor também ratifica na tradição judaica quais são os aspectos essenciais da existência religiosa que encontram expressão nos sentimentos anteriormente mencionados, pela prática que se apresenta na adoração, na ciência e na ação. Em suas palavras: "Os três são um para alcançar um único destino. Pois foi isto o que Israel descobriu: o Deus da natureza é o Deus da história, e o caminho para conhecê-lo é fazer a sua vontade" 5 .

Dentro dessa perspectiva, tanto se descobrem as bases nas quais se funda o solo para a trajetória em direção à experiência transcendente do fenômeno religioso, como se encontram definições que esclarecem o modo pelo qual se dá o acesso à percepção da realidade espiritual na consciência religiosa.

Portanto, faz-se necessário entender o que Heschel define como o $e u$, a alma e a razão, a fim de nos aproximarmos da compreensão espiritual

\footnotetext{
${ }^{4}$ Abraham Joshua HESCHEL, O homem não está só. São Paulo: Paulinas, 1974, p. 212.

${ }^{5}$ Abraham Joshua HESCHEL, Deus em busca do Homem. São Paulo: Paulinas, 1975, p. 51.
} 
dos sentimentos da narrativa bíblica, quando o profeta exclama: "Erguei os olhos e contemplai" ${ }^{6}$. Pergunta-nos, Heschel, como pode um homem erguer seus olhos para enxergar uma luz maior que ele mesmo? Responde-nos a esta questão com um paradoxo. Por um lado, o humano é feito de matéria densa destinada à decrepitude e à morte; por outro, é capaz de transcender a essa condição num olhar que o leva além de sua materialidade, com a consciência de que em sua própria existência revelase a divindade de sua natureza espiritual. Tal conhecimento resulta do engajamento em atividades que dizem respeito à ação suscitada pela experiência com o transcendente, quando seu desempenho ganha significado ao se realizar na obra da criação. Para tanto, observaremos também os três caminhos que nos levam à presença de Deus e as dificuldades que sentimos na atualidade em relação ao religioso junto às categorias fundamentais da consciência do inefável.

\section{2 - O tempo e a eternidade}

Podemos compreender profundamente a idéia do autor de que a eternidade tem como antônimo a difusão e não o tempo. Heschel entende também a eternidade como sinônimo de unidade, em que o passado e o futuro não estão separados. "A eternidade não começa quando o tempo chega ao fim. Tempo é eternidade partida em espaço, como um raio de luz refrangido na água" ${ }^{7}$.

Partindo-se da premissa do tempo, considerado como um raio de luz refrangido na água, portanto, deduz-se que é no tempo que se encontra a luz. Desse modo, percebemo-nos como seres de luz no tempo, descobrindo-nos inseridos no espaço da dimensão sagrada da realidade. Nesse momento nos sentimos um com Deus. Revela-se o aspecto sobrenatural da condição humana com Deus, sensível à consciência inefável da vida eterna, num estado ao qual buscamos sempre retornar. Nesse breve instante da existência, nossa compreensão da morte ganha outro significado, pois ela consiste num fim em si mesma. Compreendemos que se realiza na extinção, portanto, indo de encontro a seu destino na dimensão do mundo natural. De outro modo, a eternidade

\footnotetext{
${ }^{6}$ Abraham Joshua HESCHEL, O último dos profetas. São Paulo: Manole, 2002, p. 58.

${ }^{7}$ Abraham Joshua HESCHEL, O Homem não está só, op.cit., p.116.
} 
da vida apresenta-se como constante movimento e como vibração de luz infinita no tempo, um fluxo eterno da existência. Heschel compreende que:

\begin{abstract}
Os dias da nossa vida, ao contrário de fugazes, são representantes da eternidade e devemos viver como se o destino de todo o tempo dependesse totalmente de um só momento. Visto como temporalidade, a essência do tempo é separação, isolamento. Um momento temporal é sempre solitário, sempre exclusivo. Dois instantes nunca podem estar juntos, nunca podem ser contemporâneos. Visto como eternidade, a essência do tempo é união, comunhão. É no tempo e não no espaço que podemos comungar, adorar, amar. É no tempo que um dia pode valer mil anos. As intuições criativas desenvolvem-se durante uma vida inteira para durar um momento. Contudo, permanecem para sempre. Pois permanecer significa estar em comunhão com Deus, "aderir a ele" (Dt 11,22). Um momento não tem outro momento contemporâneo dentro do tempo. Mas na eternidade cada momento pode tornar-se contemporâneo de Deus. ${ }^{8}$
\end{abstract}

A elaboração deste conceito nos permite compreender melhor a importância do Schabat para a vida do homem religioso. Nesse dia dá-se a experiência em amplo espectro da dimensão divina da realidade. Segundo Heschel, a santidade do Schabat não é algo para a qual se olhe fixamente e da qual devamos humildemente nos afastar. Pelo contrário, nesse dia celebra-se a participação da presença divina no tempo, compartilhada pelo homem em todo o seu esplendor. O autor afirma: "É santo, não longe de nós. É santo para nós, 'Guardai o meu Schabat porque ele deve ser santo para ti'. (Êxodo 31;14). 'O Schabat adiciona santidade a Israel', (Mekilta ao 31:14)” 9. No que se refere à sua função, segue o comentário nas palavras do autor:

O que o Schabat confere ao homem é algo real, quase aberto à percepção, como se uma luz, que brilha de dentro, que de sua face resplandece. "Deus abençoou o sétimo dia" (Gênese 2:3): "Ele o abençoou com a luz de um rosto de homem: a luz de um rosto de homem, durante a semana, não é a mesma que a de uma no Schabat (Gênese rabá 11,2.). ${ }^{10}$

\footnotetext{
${ }^{8}$ Ibid., p. 213. Algumas citações, mesmo em destaque, encontram-se entre aspas, conforme o texto original, sendo os grifos do próprio autor.

${ }^{9}$ Abraham Joshua HESCHEL, O Schabat. São Paulo: Perspectiva, 200o, p.123. Quanto ao Schabat, trata-se do tema central nessa discussão, pois é considerado um dia de elevada representatividade para o judaísmo. Recomendamos a leitura do livro citado para aprofundar o conhecimento a respeito de seu importante significado para a piedade judaica.
}

${ }^{10}$ Ibid., p. 123. 
Segundo Heschel é antiga a concepção de que o Schabat e a eternidade correspondem ao uno ${ }^{11}$ ou participam da mesma essência. Esse dia é dado por Deus a pedido dos homens, como um exemplo neste mundo do mundo vindouro. Daí a importância de sua observância para o povo judaico, pois é o conhecimento da eternidade, ofertado a ele, como presente precioso, por Deus, O Todo Poderoso de Israel, desde que se cumpram os seus mandamentos (mitzvót). Nele, Schabat, não há diferenças entre os homens de nenhuma ordem, a fraternidade une a todos como semelhantes, compartilhando a presença divina na condição de príncipes, ou seja, como filhos do Rei:

O Schabat serve de exemplo do mundo vindouro e o mundo vindouro é caracterizado pelo tipo de santidade que o Schabat tem neste mundo (...) "O Schabat possui uma santidade como aquela do mundo vindouro". Esse dia santo "o Sétimo dia e é o sinal da ressurreição e do mundo vindouro, e não poderá haver, portanto, luto neste dia”. ${ }^{12}$

Heschel diz que, embora a tradição judaica não nos ofereça definição do conceito de eternidade, a sacralização do tempo é como experimentar o gosto da eternidade ou da vida eterna no tempo. A vida eterna não se desenvolve longe de nós; ela é plantada dentro de nós, desenvolvendo-se além de nós. $\mathrm{O}$ autor compreende o mundo por vir não como uma condição póstuma, ou seja, após a partida do corpo, mas, ao contrário, como algo atualizado na vida, no próprio ato de santificar o sétimo dia. Certamente, conforme o autor, está em posse do homem a possibilidade terrena do dia santificado. ${ }^{13}$

Interessante refletir sobre o que o autor compreende por difusão (espalhar), isto é, como algo oposto de eternidade. Equivale, todavia,

\footnotetext{
${ }^{11}$ Cf. Ibid., p.121-122, “... não se chegou ao monoteísmo por meio de redução numérica, diminuindo a multidão das divindades ao menor numero possível. Um significa único. (...) Dizer que ele é mais que o universo seria o mesmo que dizer que a eternidade é mais que um dia. De uma coisa temos certeza: sua essência é diferente de tudo o que somos capazes de conhecer ou dizer. Ele não é só superior, ele é incomparável. Não há equivalente do divino. Ele não é um aspecto da natureza, não é uma realidade adicional que existe juntamente com este mundo, mas uma realidade que está acima e além do universo. (...) Deus é um. Isto significa que só ele é verdadeiramente real. Um significa exclusivamente, nenhum outro a mais, nenhum outro além de, só somente".
}

${ }^{12}$ Abraham Joshua HESCHEL, O Schabat, op. cit., p. 105-106.

${ }^{13}$ Cf. Ibid., p. 107. 
questionarmos se não será esta a dicotomia da qual Heschel nos fala, sobre nossa percepção da realidade? Não equivale a dizer sobre a nossa visão estreita e parcial a respeito do mundo? Segundo Heschel, para a piedade judaica a extrema dicotomia humana não é a da mente e da matéria, mas, sim, a do sagrado e do profano ${ }^{14}$.

Heschel propõe-nos paradoxos e abala crenças que julgamos satisfatórias, na idéia onipotente da razão ter autonomia em si mesma, conduzindo a alma por um percurso inédito entre os escaninhos da mente indo ao encontro do inefável. Diz que nosso conhecimento do profano implica estarmos acostumados a pensar que a alma é um autômato. Esclarece-nos que a finalidade da lei do Schabat é a de tentar dirigir o corpo e a mente para a dimensão do sagrado, ensinando que o homem não está somente em relação com a natureza, mas também em relação com o criador dela. Recoloco-nos frente à vida, que, para o autor, apresenta-se menos como um enigma e mais como um grande desafio.

Quando experimentamos dolorosos conflitos, que, por vezes, nossa mente tenta em vão aplacar, arriscamo-nos a responder ao desafio de confrontar a

eternidade. Neste momento, Heschel afirma que, apesar de nossa visão fragmentada e dispersa da realidade, fruto da nossa condição humana, temos a oportunidade da integração que nos é oferecida pelo Schabat, que é o Espírito na forma do tempo, onde é possível santificar o tempo, alçando o bem no plano do santo, e de contemplar o sagrado, abstendo-nos do profano. Profano, entendido em suas palavras, na seguinte analogia: "Usualmente pensamos que a terra é nossa mãe, que o tempo é dinheiro e, o lucro nosso companheiro. O sétimo dia é um lembrete de que Deus é nosso pai, de que o tempo é vida, e de que o espírito é nosso companheiro" ${ }^{15}$. Portanto, conforme a Torá, oferece-nos um caminho que conduz à unidade pelo mergulho profundo nas raízes. No fluxo da vida onde podemos encontrar-nos unidos, neste mundo, pela misericórdia divina, quando se refere à seguinte passagem bíblica: "As coisas criadas nos seis dias Ele as considerou bem, o sétimo dia Ele fê-lo santo" ${ }^{16}$.

\footnotetext{
${ }^{14}$ Cf. Ibid., p. 108.

${ }^{15}$ Abraham Joshua HESCHEL, O Schabat, op.cit., p.109.

${ }^{16}$ Ibid., p. 108.
} 
Heschel resgata também a importância da revelação na Torá, que até os nossos dias reverbera como um evento supranatural que sucedeu ao povo judeu no Monte Sinai. Essa concepção do autor a respeito da eternidade e do supranatural permite-nos, por fim, compreender aquilo que ele define como o conceito central do judaísmo: o Deus vivo. E, possibilita-nos também acompanhar sua reflexão pelos sutis meandros do conhecimento, que aludem à seqüência de elaborações na dimensão temporal da realidade, que se desvelam na tessitura mística implícita nas atitudes, ou seja, no aspecto exeqüível (prático) do pensamento religioso judaico, que se expressa como a mística da ação.

\section{3 - Os três caminhos}

Segundo Heschel, há três pontos de partida para a contemplação de Deus; três veredas que conduzem a ele.

A primeira é o caminho do sentimento da presença de Deus no mundo e nas coisas. Ao se encontrar frente à maravilha e ao esplendor que inspira a natureza, origina-se a admiração questionada pelo profeta, citado por Heschel, na seguinte passagem de Isaías 40,26: "Levantai ao alto vossos olhos, quem criou estas coisas?" ${ }^{17}$.

A segunda via encontra-se no caminho do sentimento de sua presença na Bíblia, na afirmação imperativa quando Deus se apresenta ao homem e diz: "Eu sou o Senhor teu Deus" (Ex 20,2) ${ }^{18}$. Esta afirmativa desperta nossa consciência ao compromisso emergente de se agir segundo Seus mandamentos.

A terceira via compreende o caminho do sentimento de sua presença nos atos sagrados. Quando O percebemos pelos rituais, compartilhamos de sua presença. A vida consagra-se no pacto firmado de que "Tudo o que o Senhor tem falado, faremos" (Ex 24,7) ${ }^{19}$.

Por conseguinte, o autor entende que para se dar a consciência do inefável, é preciso sensibilizar-se à percepção da presença da dimensão espiritual, pois para “... recapturar os insights encontrados nesses três

\footnotetext{
${ }^{17}$ Abraham Joshua HESCHEL, Deus em busca do Homem, op. cit., p. 5o. De acordo com Bahya, apud Ibid., p. 50: "é nossa obrigação meditar sobre as maravilhas manifestadas nas criações de Deus, para que elas possam servir como evidência da existência de Deus".

${ }^{18}$ Ibid., p. 51.

${ }^{19}$ Ibid., p. 51.
} 
caminhos é preciso retornar às raízes da experiência bíblica, na visão do Profeta, da vida e da realidade" ${ }^{20}$. Deste modo, é possível viabilizar a adoção de um modo de vida religioso, como um meio eficiente de realizar um único destino, nossa resposta à pergunta de Deus. O que não pode se dar sem a dedicação ao estudo da Torá, imprescindível para o conhecimento, o ouvir a palavra divina e, no sentido de praticar, o fazer, que concerne à fé depositada na Palavra. Vale comentar a esclarecedora citação de Leone, em seu livro A imagem divina e o pó da terra:

\begin{abstract}
No livro Deus em busca do homem, de 1955, Heschel define o homem como sendo uma necessidade de Deus. Essa noção, derivada da mística judaica, afirma que Deus necessita do homem para que por meio dele possa realizar na história humana o tikun, isto é, o conserto redentor, pelo qual o homo sapiens por seus próprios atos viria a se humanizar. A humanização, como podemos ver, sendo uma tarefa do próprio homem, é também um ato sagrado. É dessa forma que Heschel interpreta o versículo bíblico, que diz: "Deveis ser santos, como teu Deus é santo" (Lev. 19:2) Este é outro aspecto do ser humano com a dimensão divina em busca de sua auto-humanização. (...) a realização de uma mitzvá santifica aquele que a realiza. Santificar tem em si um sentido de imitar o ato divino, de aproximar o homem de Deus, de torná-lo a imagem divina. Essa noção da importância da mitzvá perpassa toda a tradição judaica. ${ }^{21}$
\end{abstract}

Esclarece-nos, portanto, o que diz Heschel: "A meta de todos os esforços é alcançar a restituição da unidade de Deus e do mundo. A restauração desta unidade é um processo constante e a sua realização será a essência da redenção messiânica" ${ }^{22}$. Esta restauração do mundo é compreendida como a parte que diz respeito ao nosso desenvolvimento espiritual e se torna efetiva na esfera das ações, quando o homem participa da construção do mundo, criando uma realidade mais divinamente humana. Podemos depreender, então, o que para Heschel significa pesquisar o drama religioso de Israel e buscar compreender o que autorizou Jó a dizer nos seguintes versos:

\footnotetext{
${ }^{20}$ Ibid., p. 51

${ }^{21}$ Alexandre LEONE, A imagem divina e o pó da terra. São Paulo: Humanitas-FFLCH/USP-FAPESP, 2002, p.179-180.
}

${ }^{22}$ Abraham Joshua HESCHEL, O Homem não está só, op. cit., p.117. 
Porque eu sei que o meu Redentor vive, E que no último dia ressurgirei da terra. Serei novamente revestido de minha pele,

E na minha própria carne verei a Deus. Eu mesmo o verei,

E os meus olhos o hão de contemplar, E não outros.

Esta é a herança que está depositada no meu peito. (Jó 19,25-27)23

Nessa exposição dos versos de Jó, que tem o profeta como referência, o autor formula-nos a questão capital: "Como fazer um homem atingir um estágio de pensamento onde ele esteja apto para dizer: E na minha própria carne verei a Deus?” ${ }^{24}$. É grave o desafio dessa questão, visto o panorama atual apontar para o ceticismo com que o homem se relaciona com a dimensão espiritual. Vemos que ele a experimenta com um total distanciamento da realidade, pois adota as explicações dos fenômenos como respostas finais a sua angústia, sem levar em consideração sua condição de insuficiência.

\begin{abstract}
Segundo Leone, para o humanismo hescheliano, a questão humana não pode se resumir à noção conceptual de que compartilhamos com os outros seres uma existência no Ser, como sugere Heidegger. É vivendo por meio de suas ações, que o homem adquire o conhecimento do sentido de sua existência. As noções heschelianas não oferecem uma definição prévia do homem. Pelo contrário, é respondendo as demandas de sua vida que o homem dá sentido à sua existência. Não porque a vida seja absurda e careça de sentido, mas porque para ele o encontro com o sentido é o encontro com o inefável, com o misterioso. ${ }^{25}$
\end{abstract}

No entanto, para atingir um estágio de pensamento apto para apreender a visão cantada nos versos de Jó, é fundamental sermos tocados pela fé, dádiva divina e fonte irrefutável da confiança no milagre da graça. Essa fé provém da consciência da experiência momentânea e fugaz e da breve sensação de sermos um com Ele. Essa experiência estabelece-se no plano físico e é desse modo, para o autor, que a espiritualidade convertese à prática e se desdobra em seu grau máximo para o cotidiano. Por

\footnotetext{
${ }^{23}$ Idem, Deus em busca do Homem, op. cit., p. 51.

${ }^{24}$ Ibid., p. 52.

${ }^{25}$ Alexandre LEONE, A imagem divina e o pó da terra, op. cit., p. 218.
} 
conseguinte, para realmente compreender a resposta bíblica é fundamental atender a necessidade de determinar qual é nossa pretensão no mundo e, então, empenhar esforços não só para compreender as categorias do sublime, maravilhoso, mistério, temor e glória, como também desfrutar do resultado. ${ }^{26}$

\section{4 - Oração}

A oração consiste num dos três caminhos, propostos por Heschel, para o desenvolvimento da consciência religiosa, como ação precedente para estabelecer um encontro com o divino. Encontra-se na oração uma maneira de meditar e se absorver na realização divina, mantendo os insights do maravilhoso constantemente ativos, pela adoração diária.

O autor esclarece que a origem da oração é o sentido dos milagres e das maravilhas, que diariamente experimentamos, e representa um caminho de profunda e perpétua consciência da maravilha de ser. A função da oração cumpre-se no mandamento da Torá do exercício cotidiano, isto é, a atitude da consciência religiosa do judeu de orar três vezes por dia. Heschel explana a importância do orar dizendo que: "toda tarde nós recitamos: 'Ele criou a luz e fez a treva. Duas vezes por dia nós dizemos: 'Ele é único'”27. E explica a diferença entre o significado de tal repetição e o de uma teoria cientifica que, uma vez anunciada e aceita, não precisa ser repetida duas vezes por dia. Porém, os insigths do maravilhoso devem ser conservados constantemente ativos, pois, no entender do autor, desde que haja necessidade de prodígios diários, há necessidade de adoração diária. Nesta atitude o homem tem participação ativa na criação. ${ }^{28}$

Heschel adjudica que o senso a respeito do maravilhoso sustenta-se através da oração ante os atos triviais de todas as atividades que compreendem as necessidades humanas. Por exemplo, ora-se perante o prazer do alimento ou o beber um copo de água, realizando cada ato como uma referência ao supremo milagre: "Abençoado sejas... por cujas

\footnotetext{
${ }^{26}$ Cf. Abraham Joshua HESCHEL, Deus em busca do Homem, op. cit., p. 52.

${ }^{27}$ Ibid., p. 72.

${ }^{28}$ Cf. Ibid., p. 72 .
} 
palavras todas as coisas se tornaram” ${ }^{29}$. Então, em todas as situações vividas, quer nos deleitemos ou não, ou mesmo, ouvindo boas ou más notícias, invocamos seu grande nome afirmando nossa consciência de sua presença. Até mesmo quando o corpo cumpre sua função fisiológica, dizemos: "Abençoado sejas que saras toda carne e fazes maravilhas"30.

Para aprofundar a compreensão dos sentidos da oração, é importante notar a distinção, feita por Heschel, de que a “... consciência do maravilhoso não é a mesma coisa que saber as maravilhas que nos ocorrem. As maravilhas ocorrem sem que estejamos aptos para percebêlas" ${ }^{31}$. Pois, sem dúvida, no momento em que tomamos esta consciência do maravilhoso, se opera em nós uma atitude de respeito que, de alguma forma, nos envolve por inteiro. Não nos é mais possível ignorar a Presença. Ela nos obriga ao confronto de tal modo que, mesmo que tentemos evitar, nos rendemos a esta força superior pelo intenso sentimento que desperta da reverência. Desta forma, a questão última nos coloca frente ao mistério da vida, reivindicando nossa plena consciência da atitude expressa num compromisso ético de servi-La. ${ }^{32}$ Nas palavras de Heschel:

... esta é uma das metas do modo de vida judaico: experimentar necessidades triviais como empreendimentos espirituais, sentir o amor oculto e sabedoria em todas as coisas. No Cântico do mar Vermelho, lemos:

Ó Senhor, quem é como tu entre os deuses?

Quem é como tu glorificado em santidade,

Terrível em louvores, obrando maravilhas? (Ex 15,11) ${ }^{33}$

Heschel comenta aquilo que os rabinos observaram:

Não está escrito aqui: Quem fez maravilhas, mas: Quem faz maravilhas...

Ele fez e ainda faz maravilhas para nós em cada geração, como foi dito:

Maravilhosas são as tuas obras,

E minha alma o sabe muito bem. $(\mathrm{Sl} 139,14)^{34}$

\footnotetext{
${ }^{29}$ Ibid., p. 73 .

${ }^{30}$ Ibid., p. 73 .

${ }^{31}$ Ibid., p. 75 .

${ }^{32}$ Cf. Ibid., p. 73 .

${ }^{33}$ Ibid., p. 73 .

${ }^{34}$ Ibid., p. 73-74.
} 
132 | Veritas | Porto Alegre, v. 63, n. 1, jan-mar. 2018, p. 121-149

O autor cita também um comentário do sábio Nahmanides sobre Êx 13,16 que diz o seguinte:

A crença nos milagres ocultos é a base para a Tora inteira. Um homem não toma parte alguma na Tora, a menos que creia que todas as coisas e todos os eventos da vida do individuo tanto quanto na vida da sociedade são milagres. Não há nenhuma coisa como o curso natural dos eventos. ${ }^{35}$

Por outro lado, para Heschel, o sentido do maravilhoso e transcendental não deve tornar-se um meio para o intelecto se acomodar, entendendo que:

Não deve ser um substituto de análise onde é possível uma análise; não deve reprimir a dúvida onde a dúvida é legítima. Deve, contudo, permanecer uma consciência constante se o homem fiel à dignidade a respeito da criação de Deus, deve ser porque tal consciência é a fonte de todo pensamento criativo. ${ }^{36}$

\section{5 - Dificuldades na atualidade}

Um dos pré-requisitos para alguém alcançar a consciência de Deus no mundo, é efetuar a observância dos mitzvot, ou seja, dos mandamentos descritos como procedimento determinado para inúmeras situações existenciais específicas, segundo instruções detalhadas na Torá. Através destas atitudes, podem vir a ser despertados os sentimentos de sublime, prodígio, maravilhoso, mistério, temor e glória. Com isso, realizase, na esfera emocional, a religiosidade e a necessidade do homem ser submetido ao mistério e aderir ao inefável, como condição sine qua non para elevar-se espiritualmente, destacando o ponto de vista do autor:

A grande premissa da religião é que o homem está apto para superar-se; que o homem, como parte que é parte deste mundo, pode manter uma comunhão com Ele, que é maior do que o mundo; que o homem pode elevar seu intelecto e apegar-se ao absoluto, que o homem, que é condicionado por múltiplos fatores, é capaz de viver com exigências que sejam incondicionadas. Daí apresenta-se a questão de como fazer com que o homem possa elevar-se acima do horizonte de sua mente? Ou libertar-

\footnotetext{
${ }^{35}$ NAHAMANIDES apud Abraham Joshua HESCHEL, Deus em busca do Homem, op. cit., p. 76. ${ }^{36}$ Ibid., p. 76 .
} 
se das perspectivas do ego, grupos, terra e tempo? Como fazer alguém encontrar um caminho neste mundo que o leve a uma consciência a respeito dele, que está além deste mundo? 37

Heschel, como pensador religioso, refere-se ao eu, a partir de uma categoria que entende o ser na dimensão transubjetiva da realidade espiritual. Conduz-nos à dimensão de compreensão do ser humano para além dos conceitos formulados na psicologia, não obstante se utilize do conceito de ego. Compreende o universo como uma imensa alusão e nossa vida interior como uma citação anônima. Numa interrogação que transcende as palavras, o autor questiona se está em nosso poder verificar a citação, identificar a fonte e saber o que todas as coisas representam. ${ }^{38}$ Postula ser necessário de nossa parte, além de uma profunda consciência da incongruência de todas as categorias, a noção da onipresença sem nome e do impenetrável mistério. Premissa considerada pelo autor como prérequisito para os esforços na busca de uma resposta. Heschel trabalha no sentido de demonstrar as falhas no sistema de compreensão que são utilizadas frente às questões últimas, e do cuidado necessário em não se adulterar ou mesmo sufocar a pergunta incomparável com formulações inadequadas, para obterem-se, no mínimo, respostas finais razoáveis. ${ }^{39}$

O tópico fundamental da religião versa em torno das seguintes questões: quem é o grande autor? Por que existe um mundo? Qual o sentido da nossa vida? Em seu ponto de vista, são para estas perguntas que, apesar de nossas conquistas e poder, não sabemos em que porta bater em busca de alívio para nossas ansiedades. Na opinião do autor, "sabemos como age a natureza, mas não por que e por causa de quem, sabemos que vivemos, mas não por que nem para quê. Sabemos que temos de indagar, mas não sabemos quem plantou dentro de nós o anseio da indagação" $4^{\circ}$.

Estas perguntas têm como resposta para Heschel a atitude do homem moderno que foge do metafísico, assim como tende a suprimir seu sentido inato e a sufocar as perguntas que transcende a sua mente, procurando refugiar-se nos limites do seu eu finito. Arroga à atitude de indiferença pela realidade espiritual, como conseqüência da força do

\footnotetext{
${ }^{37}$ Ibid., p. 52.

${ }^{38}$ Cf. Abraham Joshua HESCHEL, O Homem não esta só, op. cit., p. 51.

${ }^{39}$ Cf. Ibid., p. 52.

${ }^{40}$ Ibid., p. $5^{2}$.
} 
agnosticismo sobre a razão, quando proclama a ignorância sobre a realidade última e acredita, como única atitude honesta a ser almejada, a negação da existência de Deus. Heschel compreende que tal atitude se resume numa armadilha inconsistente e auto-ilusória.

Para Heschel, declaramos como inatingível aquilo que somos incapazes de conhecer e, nessa medida, nos abstraímos da questão. Em suas palavras: "Esta alegação de que não existe uma significação última ressoa estridentemente no profundo silêncio do inefável" ${ }^{41}$. Por decorrência, retirando-nos para dentro dos limites do próprio eu e, ao nos evadirmos da questão suprema, reduzimo-nos à percepção de que:

...a consciência do maravilhoso é muitas vezes dominada pela tendência da mente em dicotomizar, que nos faz olhar o inefável como se fosse uma coisa ou um aspecto das coisas longe de nós mesmos, como se somente as estrelas estivessem circundadas com o halo do enigma e não a nossa própria existência. A verdade é que o eu, nosso "senhor", é algo desconhecido, inconcebível em si mesmo. Penetrando-o descobrimos o paradoxo de não conhecermos o que supomos conhecer tão bem. ${ }^{42}$

Heschel, nessa discussão, compreende que ao não diferenciarmos a condição humana em seus aspectos, ou seja, a condição do estado natural do sobrenatural, sobrevém à dicotomia do pensamento relativo à sua divindade. A compreensão do conceito de eu se reduz ao de ego, naquilo que se refere à identidade em seu aspecto misterioso de semelhança com o divino. Para ele, o que nós chamamos eu, encontra sua origem no inefável. Entende que as idéias pautadas em símbolos como convicções de que comumente fazemos uso, não nos permitem penetrar o sentido total do ser. Reporta-nos às origens, pois para ele, o que desejamos expressar está submerso na profundeza insondável do inconsciente. Segundo o autor:

Além do meu alcance está o fundo da minha própria vida interior. Não estou certo nem sequer de que a voz que sai de mim é a voz de uma unidade pessoal definida. O que na minha voz se originou em mim e o que é a ressonância da realidade transubjetiva. Ao dizer "eu”, minha intenção é diferenciar a mim mesmo de outras pessoas e outras coisas. (...) só pode

\footnotetext{
${ }^{41}$ Ibid., p. 53.

${ }^{42}$ Ibid., p. 53 .
} 
ser separado distintamente das suas ramificações, isto é, de outros indivíduos e de outras coisas, mas não das suas raízes. ${ }^{43}$

A verdade, para Heschel, é que o "eu" em si mesmo é uma realidade transcendente encoberta. Então ele menciona os momentos em que, por vezes, sentimos estranheza dentro da nossa consciência normal, como se estivéssemos num estado de transe, e algo experimentamos como se a nós fosse imposto e se a nossa própria vontade não nos pertencesse. $\mathrm{O}$ autor descreve a experiência de um estado alterado de consciência, freqüentemente atribuído às vivências religiosas.

Heschel considera indiscutível a sensibilidade humana ao sublime e à beleza da natureza, e, para ele no mínimo, aquele que não a percebe, torna-se indigno de ser considerado humano. Na visão do autor, o que está sob o domínio da nossa percepção do mundo são os aspectos da natureza que mais nos chamam a atenção: "sua força, beleza e grandeza, bem como o modo de nos relacionarmos com o mundo, ao explorá-lo, ao desfrutá-lo, e ao temê-lo pela sua magnitude" ${ }^{44}$. A posição do homem frente a ela é expressa pelo modo que suas atitudes buscam realizar, principalmente, a auto-satisfação, pois, "a força, ele a explora. A beleza é para o seu gozo. E a grandeza enche-o de admiração" ${ }^{45}$, como se tudo que nela existe estivesse ali para servi-lo.

Este exemplo constata como os valores têm sido colocados de forma a não nos auxiliar no despertar desses sentimentos. Heschel afirma que em nossa época a força constela-se como o bem maior, dote capaz de desbravar a natureza e de transformá-la para a eficácia na utilização de recursos. E essa exploração da natureza, para o autor, atualmente representa o maior propósito tido pelo homem na criação de Deus, dizendo que: "O homem tem, naturalmente, se tornado o animal fabricante de ferramentas para a satisfação de suas necessidades, de uma forma cega e inconseqüente" ${ }^{4}$.

Esta preocupação de Heschel pode ser notada, observando-se o resultado dramático dessa inconseqüência, que testemunhamos na resposta da

\footnotetext{
${ }^{43}$ Idem, Deus em busca do Homem, op. cit., p. 54.

${ }^{44}$ Ibid., p. 53.

${ }^{45}$ Abraham Joshua HESCHEL, O homem não está só, op. cit., p.15.

${ }^{46}$ Abraham Joshua HESCHEL, Deus em busca do Homem, op. cit., p. 53.
} 
natureza frente a sua exploração desmesurada e constatamos em todo mundo a manifestação de ocorrências de poderosas catástrofes naturais. Heschel, numa crítica contundente ao homem moderno, que prioriza o conhecimento com fins pragmáticos utilitários, salienta que venerar é mais importante que compreender:

Os gregos aprendiam a fim de compreender. Os hebreus aprendiam a fim
de venerar. O homem moderno aprende a fim de usar. A Bacon devemos
a formulação "saber é poder". Assim é que as pessoas são impelidas a
estudar, saber significa sucesso. Não sabemos mais como justificar
qualquer valor exceto em termos de experiência. O homem está propenso
a definir-se como "aquele que busca o máximo de conforto pelo mínimo
dispêndio de energia". Ele compara o valor com aquilo que avalia. Ele
sente, age e pensa como se o único propósito do universo fosse satisfazer
suas necessidades. ${ }^{4}$

Estamos cônscios de que há em jogo um grande sistema que envolve fortes interesses econômicos para perpetuar a condição de alienação, ao qual convém a manutenção e a maximização da demanda de consumo exagerado, o que redunda na indiferença da consciência social, fadada a se esquivar de seus problemas mais fundamentais. Não há lugar para a vida interior, para a experiência da subjetividade e muito menos tempo hábil que não seja para atender, tal qual máquina ou robô, a pressão externa exercida pela alta demanda de produtividade.

O vazio de sentido, a dor e o sofrimento emocional são experiências de sentimentos, de percepções realísticas que fazem parte da vida, do ser no mundo, quando ao mínimo sinal de tristeza manifestado pela pessoa é tido como depressão e imediatamente medicado. A pessoa, quando medicada, encontra alívio para esses sintomas, mas tem enfraquecida sua força para lidar com a realidade e a pertinência de suas percepções. Aos poucos, a resposta do organismo como um todo fica comprometida. Atualmente temos como exemplos comuns tanto a síndrome do pânico (conjunto de sintomas que expressam grande dificuldade do sujeito lidar com a realidade que se apresenta de forma ameaçadora, levando-o a exclusão do convívio com os demais), como também a fibromialgia (dor generalizada

\footnotetext{
${ }^{47}$ Ibid,. p. 53. Não há dúvida a respeito da ampla importância do desenvolvimento científico da pesquisa em geral e na medicina em particular, beneficiando-nos amplamente. Mas a questão a ser levantada tem como ponto crítico o que se dá no uso indiscriminado da droga que se presta a sanar a solidão e a falta de sentido de vida que tanto afligem a alma do ser humano contemporâneo.
} 
nas fibras musculares), tida por alguns como um sintoma similar, em nosso século, da histeria.

Pois é fato que em algum momento da vida, quem de nós não se percebe experimentando a agitação do manancial de forças irracionais emergindo das situações críticas de insatisfação, tanto no plano individual como no coletivo, causando-nos medo, se não, por vezes, terror? O que na realidade é uma percepção sutil do medo encontra-se escamoteada na oferta de felicidade a qualquer preço, e na busca desenfreada da eterna juventude, nos produtos descartáveis e na vida descartável, na produção da imagem e semelhança da beleza comercializada, sucumbindo à idolatria do poder aquisitivo. Na visão de Heschel:

O homem moderno, tendo atingido o estágio final, tem evitado todo apelo em direção a entidades inobserváveis. (...) Ofuscados pelas brilhantes realizações do intelecto no campo da ciência e da técnica, nós não nos convencemos apenas de que somos os senhores da terra; nós nos convencemos também de que nossas necessidades e interesses são o padrão fundamental do que está certo ou errado. Conforto, bens materiais e sucesso tentam, continuamente, nossos apetites, diminuindo nossa visão daquilo que é requerido, mas nem sempre desejado. Essas coisas tornaram fácil para nós o aumento da cegueira pelos valores. Os interesses são o cão do homem; 'estima-cegueira', seu explorador e guia..$^{4}$

Metaforicamente, vemos o temor e o tremor deslocados para a experiência do corpo e da mente, que ficam adoecidos, num estremecimento do homem frente ao insondável e numa reverência a um mundo sem Deus. Para o autor, a fé suprema nas estatísticas e a total negação da idéia de mistério tornam o homem insensível à dimensão espiritual da vida e desvalorizam o conhecimento religioso, instigando a dúvida em detrimento da fé. Em conseqüência, o homem ao se tornar, nas palavras de Heschel: "Indiferente àquilo que lhe falta, deixou de confiar na sua vontade de crer ou até mesmo de entristecer-se, pelo esforço inútil no desejo de crer" ${ }^{49}$.

Heschel analisa a precariedade nos relacionamentos e a compreende, principalmente, como um dos males de nosso tempo, causados pela falta de confiança que depositamos na natureza humana.

\footnotetext{
${ }^{48}$ Abraham Joshua HESCHEL, Deus em busca do Homem, op.cit., p. 55.

${ }^{49}$ Ibid., p. 53-54.
} 
Pensa ele que estamos inclinados a ver o mundo como um pandemônio, quando criticamos sua ausência de senso de virtude e de integridade. Mesmo que se corrompa a bondade por puro egoísmo, saboreamos a auto indulgência em todos os valores. De outro modo, não fazemos outra coisa a não ser violar a verdade com evasivas, tecendo todas essas críticas de forma contundente ao modo em que as coisas se nos apresentam.

Porém, desejamos que a idéia de honestidade seja mantida e a pureza seja como o enquadramento do círculo da natureza humana. Para o autor, essa atitude resulta na histeria da suspeita (paranóia), que nos tornou desconfiados uns dos outros, e na perda de confiança em nossas aspirações ou convicções. Deste modo, em "nosso pensamento, partimos do princípio da suspeita e não da dúvida" ${ }^{0}$.A partir dessa reflexão, o autor questiona a visão da psicologia, quando esta reduz a interpretação da crença religiosa à satisfação de desejos inconscientes e Deus a uma projeção de emoções egoístas. Mas, o que realmente lhe parece sério observar é mais a necessidade de se buscar a prova de uma fé autentica da existência de Deus. ${ }^{51} \mathrm{Na}$ citação abaixo, constatamos a atualidade do comentário de Heschel:

Não somente nos privamos da fé; nós perdemos nossa fé no seu
verdadeiro significado. O que nós temos é um senso de pavor. Temos
medo do homem. Estamos atemorizados de nossa própria força. Nossa
orgulhosa civilização ocidental não se tem oposto à onda de crueldade e
crime que jorra de dentro da tendência interior, para o pecado, da alma
humana. Nós quase mergulhamos numa corrente de culpa e mistério que
não deixa nenhuma consciência limpa. ${ }^{2}$

Certamente compartilhamos com o autor desse apelo à consciência. A realidade que apresenta em seu comentário, sem sombra de dúvida, corresponde á angustia e impotência que sentimos. Heschel fala-nos das possíveis conseqüências que a perda de Deus causou na humanidade, e tenta recuperar nossos sentidos para a percepção da gravidade da situação abissal em que vivemos. Refere-se a algumas vertentes da psicologia, que muito têm formulado sobre a alma, tomando-a como seu objeto de estudo, reduzindo o cerne da questão religiosa da alma a uma função do

\footnotetext{
${ }^{50}$ Ibid., p.196-197.

${ }^{51}$ Cf. Abraham Joshua HESCHEL, Deus em busca do Homem, op. cit., p. 55.

${ }^{52}$ Ibid., p. 56.
} 
psiquismo. Em detrimento do seu aspecto diferencial no âmbito religioso espiritual, o autor nos adverte do perigo de tornar Deus um mero produto ou conceito do intelecto, pela racionalização da realidade divina. O risco pode ser, além da perda do profundo sentido da alma, o prejuízo dos princípios e dos valores éticos que orientam a conduta pessoal. ${ }^{53}$ Confundem-se o natural e o sobrenatural, redundando numa simplificação conceitual, na qual se perde o sentido do transcendente e junto com ele, o significado e a atitude de reverência e de veneração que despertam a presença do sagrado inefável, ponto de vista este que modifica, por vezes, de forma radical, a visão do homem a respeito de sua própria vida. Heschel diferencia a alma da razão, apesar destas advirem da mesma fonte, compreendendo que:

Quanto mais incisiva a consciência do desconhecido e mais vigorosa nossa
percepção imediata da realidade, tanto mais aguda e inexorável se torna a
nossa verificação dessa disparidade. Como o simplório identifica a
aparência com a realidade, assim o superculto identifica o exprimível com
o inefável, o lógico com o metalógico, os conceitos com as coisas. E assim
como o pensamento crítico está cônscio da sua não identidade com as
coisas, assim nossa alma em sua auto-reflexão leva no coração uma
consciência de si mesma distinta do conteúdo lógico dos seus
pensamentos. 54

O autor propõe a consciência do inefável como o ponto de partida para nossas indagações e critica a filosofia de se ter deixado seduzir pela promessa do conhecido, em detrimento, muitas vezes, dos tesouros do incompreendido mais profundo, delegando-os aos poetas e aos místicos. Concorda, entretanto, não ser possível haver problemas metafísicos sem o sentido do inefável, nem consciência do ser como ser, do valor como valor.

Heschel alude ao fato de sermos cidadãos de dois reinos, o que nos sujeita a uma dupla lealdade, que significa vivermos o sentido do inefável

\footnotetext{
${ }^{53}$ Cf. A. SAMUELS, Jung e os Pós-Junguianos. Rio de Janeiro: Imago, 1989, p.177. Na psicologia analítica, Jung corrobora esse ponto de vista, quando afirma que “... o homem tem uma tendência invencível a confundir a imagem com a realidade, a divindade no homem e o Deus transcendente, não considerando a diferença que existe entre o objeto e a imagem, apesar do caráter absoluto da experiência da Imago Dei, assim Deus, ou aquilo que é chamado Deus, é apenas considerado como expressão simbólica de uma realidade imanente ao homem, como um conteúdo psicológico, e sob esse prisma, atua no desenvolvimento da consciência como um fator natural” (Ibid., p. 177).
}

${ }^{54}$ Abraham Joshua HESCHEL, O homem não está só, op. cit., p. 20. 
num reino e nomearmos e explorarmos a realidade noutro. ${ }^{55} \mathrm{Em}$ decorrência disso, principalmente às mentes que tem paixão pelo conhecimento, devemos estar atentos ao fato, segundo o autor, de que: “... fascinados, nossas mentes apossam-se das riquezas de um mundo irresistível e, carregando nossos limitados espólios, apressadamente deixamos a terra para nos perdemos no redemoinho de nossos próprios conhecimentos" ${ }^{66}$.

A preocupação do autor atinente à perda de Deus, ou do homem como a medida de todas as coisas, numa de suas facetas, é percebida no desespero, pavor, ansiedade e indignação que experimentamos com o resultado da violência, qual moeda corrente, que a cada dia (cotidiano) somos obrigados a confrontar. A indiferença, a falta dos limites hierárquicos de respeito à autoridade e a dificuldade em frustrar-se resultam na falência dos valores básicos que estabelecem a ordem em qualquer relacionamento. O mínimo de educação e o máximo de exploração, licença em que o princípio do mais lucrativo, para satisfação dos próprios interesses, vigora. O respeito à palavra empenhada é relegado ao esquecimento, como se guardada numa memória recôndita de virtude, ética - princípio que se assenta ou que repousa no passado. A consideração com o outro tem como principal critério o descartável, de acordo com o interesse relativo ao momento, resultando em vínculos de interesse de extremo utilitarismo.

Heschel, sem dúvida, é porta-voz da angústia que ressoa em nossos sentimentos ao protagonizar a questão: "O que é possível fazer com nossa força? O que podemos fazer pelo mundo?” ${ }^{57}$. É intensa a tarefa que nos propõe e podemos concordar plenamente com o autor, quando diz: "O dilúvio de infelicidade está varrendo para fora nossos conceitos disformes” ${ }^{58}$, e exclama:

Quem é o Senhor? Nós nos desesperamos sempre que tomamos consciência dele, sempre que tornamos a alcançar a fé no seu verdadeiro significado. Naturalmente, num sistema de idéias onde conhecimento é poder, onde os valores são sinônimos de necessidades, onde a pirâmide do

\footnotetext{
${ }^{55}$ Cf. Ibid., p. 21.

${ }^{56}$ Ibid., p. 44 .

${ }^{57}$ Abraham Joshua HESCHEL, Deus em busca do Homem, op. cit., p. 56.

${ }^{58}$ Ibid., p. $5^{6 .}$
} 
ser está de cabeça para baixo - é difícil encontrar um caminho para a conscientização de Deus. ${ }^{59}$

A partir dessa reflexão, o autor deriva a idéia de que nossa força encontra-se no mundo e, conseqüentemente, estarmos absorvidos numa torrente de ouro, donde conclui que o único Deus que se pode encontrar é o bezerro de ouro. E se tomarmos a natureza como uma caixa de ferramentas, inevitavelmente transforma-se em um mundo que não se conduz além de si próprio. Heschel nos dá a entender que "somente quando a natureza é sentida como um mistério e uma grandeza é que somos impelidos a olhar além dela” ${ }^{60}$, alternativa que se encontra na consciência do inefável.

\section{6 - O Sublime e o Maravilhoso}

Quem somos nós? Qual é a natureza de nossas intenções, quais objetivos nos dão sentido à vida? São estas as questões fundamentais que nos dizem respeito e o que podemos constatar é que "a consciência da grandeza e do sublime está quase se esmaecendo na mente moderna" ${ }^{61}$. Do ponto de vista de Heschel, esse problema também existe no âmbito pedagógico (na base do ensino) e, nele encontram-se possíveis soluções. De acordo com sua crítica:

Nossos sistemas de educação dão ênfase à importância de habilitar o estudante em explorar o aspecto de força da realidade. (...) tentam desenvolver sua habilidade para apreciar o belo. Mas não há nenhuma educação para o sublime. Ensinamos como medir, como pesar. Nós deixamos de ensinar-lhes como honrar, como sentir o maravilhoso e o temor. O sentimento do sublime, a marca da grandeza interior da alma humana e algo do que é potencialmente dado a todo homem, agora se tornam um dom raro. Contudo, sem isso, o mundo se torna insípido e a alma se torna um vácuo. Aqui é onde o aspecto bíblico a respeito da realidade pode servir-nos como um guia. ${ }^{62}$

\footnotetext{
${ }^{59}$ Ibid., p. 56.

${ }^{60}$ Ibid., p. 56.

${ }^{61}$ Ibid., p. 56.

${ }^{62}$ Ibid., p. 56-57.
} 
A concepção pedagógica hescheliana é a do retorno (teshuvá) e, nesta concepção bíblica, "o judaísmo é comprometido com a noção de que a educação pode e deve atingir o homem em seu íntimo, pois seu objetivo é refinar e exaltar a natureza do homem"63. A pedra fundamental da Torá é a possibilidade de crescimento espiritual da humanidade. Heschel compreende os profetas como extremamente sensíveis às perversidades do homem e demonstram uma profunda consciência da obstinação e da insensibilidade da espécie humana. Entretanto é intensa a confiança em sua capacidade de redenção, na possibilidade de empreender ações que a redimam, para retornar a Deus e viver sob a égide da justiça e da compaixão. ${ }^{64}$

A importância da educação religiosa encontra-se na coerência entre o ensino e a vida. Para o autor, a questão é ampla e difícil. Ele atribui, em parte, o fracasso do ensino religioso contemporâneo a alguns fatores externos que causam sua ineficácia. Alude não desprezar, em geral, a influência corrosiva da atmosfera social, que neutraliza o efeito do ensino religioso, dentre eles, o fato de a criança viver a maior parte do tempo em um ambiente obcecado pela comercialização, a ostentação e o cinismo. Porém, Heschel insiste em advertir que a insipidez e a trivialização do ensino religioso estão entre as principais causas desse fracasso, tanto na falta de empenho em atingir uma profunda compreensão de Deus, quanto não possuir audácia espiritual, coragem intelectual e poder de desafio.

Afirma que a juventude não necessita de tranqüilizantes religiosos nem da religião como diversão ou passatempo. Alerta para a questão perceptível do colapso entre a comunicação dos problemas pessoais do individuo e a mensagem de nossa herança, e diz que: "Uma educação que foge das questões intelectuais ou que ignora o enfraquecimento emocional está condenada ao fracasso" ${ }^{65}$, quando o ensino é desprovido de sentido não se relaciona com a questão existencial do aluno, ou seja, não considera sua vida íntima e menos ainda seu comportamento fora da sala de aula. Heschel faz objeção ao fato de não serem levantadas questões fundamentais na sala de aula como essas que tratam, por exemplo, da forma pela qual deveríamos enfrentar o mal, qual é nossa relação com o

\footnotetext{
${ }^{63}$ Abraham Joshua HESCHEL, $O$ último dos profetas, op. cit., p.138.

${ }^{64}$ Cf. Ibid., p.139.

${ }^{65}$ Ibid., p. 136.
} 
inimigo, o que fazer com a inveja, qual é o significado da honestidade, como se deve enfrentar o problema da solidão, o que diz o judaísmo sobre a guerra, a violência e a indiferença diante do mal. Na compreensão do autor a educação religiosa é de importância vital, assim como também oferece subsídios para o enfrentamento dos obstáculos e mais significado a vida. Porém, entende que a educação é principalmente de responsabilidade dos pais, e segundo a tradição judaica, o professor não é mais que um representante deles, o que lhe exige cautela ao ensinar. Heschel tece uma crítica aos pais que não atentam para sua própria forma de agir e esperam que "as criancinhas escutem e reconheçam a voz do espírito" ${ }^{66}$.

Outra faceta que o autor considera deficiente é a descaracterização do ensino, quando a transmissão em si do legado religioso não é expressa como um acontecimento significativo para aquele que ensina. Depende da qualidade e da dedicação do mestre a tarefa da comunicação, pois como explica Heschel, "a tarefa do professor é ser como uma parteira para o aluno e uma parteira para nossa tradição" ${ }^{67}$. A relação entre ambos deve passar por momentos significativos de compartilhar insights e apreciação, apesar de reconhecer a grande dificuldade que a tarefa do ensino envolve. Nas palavras de Heschel:

A causa do fracasso da educação judaica é o declínio da fé na educação
judaica e, basicamente, na falta de fé no ensino dos valores. Nossa
premissa é a certeza de que somos capazes de educar o homem interior,
de formar e de informar a personalidade, de desenvolver não somente a
memória, mas também a capacidade de discernimento, não somente a
informação, mas também a apreciação, não somente as habilidades, mas
também o respeito, não somente a instrução, mas também a fé, não
somente o estudo, mas também o sentido dos valores. Abstendo-nos de
ensinar os valores, abdicamos da responsabilidade. ${ }^{68}$

Na visão do autor precisamos estar atentos às poderosas atividades de cultura de massa que influenciam as atitudes, e o conceito de valores veiculados pela mídia, que atingem o indivíduo como um todo, pois

\footnotetext{
${ }^{66}$ Ibid., p. 137.

${ }^{67}$ Ibid., p.137.

${ }^{68}$ Ibid., p. 138.
} 
representam uma ameaça quer à sua sensibilidade e independência, quer ao seu equilíbrio interior e liberdade. ${ }^{69}$

Portanto, para Heschel, é só quando o ser humano percebe aquilo que olha, vê e se encanta que ele pode se encontrar para além dele mesmo e tomar consciência de que isto se dá a partir do olhar de Deus. Esta é a experiência do sublime, a imprescindível consciência de aquilo que lhe parece belo, pertence à ordem do divino. Então, fica óbvio que não é o que está ao alcance de nossa visão que podemos ver enaltecidos, mas somente pode-se maravilhar quando é imediatamente reconhecida a sua fonte, o divino. ${ }^{70}$

Nessa análise Heschel assinala, na área educacional, a necessidade de propostas pedagógicas que incluam não só a valorização da experiência insondável, como também nomeá-la devidamente, ensinando às crianças a virtude das questões pertinentes ao admirável e ao sublime, sentimentos que dizem respeito ao mistério da natureza e da criação. Como observamos, quando nos fazem perguntas espantosas a respeito da vida e da morte, de seu assombro com o ecoar dos trovões que precedem a chuva, e da alegria em sentir o frescor da água que cai do céu, podemos reaprender com elas!

A surpresa, a maravilha e a excitação são expressas no primeiro contato com a natureza, o mar, as cachoeiras, as cavernas, em suma, com toda vida natural sentida como criação divina. Admiramo-nos com a profundidade de suas questões e se estas forem devidamente acolhidas e adequadamente consideradas, podem permanecer invioladas até a vida adulta, dando o suporte ou a abertura necessária à consciência da espiritualidade. Esta consciência não só apazigua os medos e as inseguranças infantis, como também representam as bases que dignificam a vida adulta. Podemos, desde o início do processo de aprendizagem e socialização, perceber como as crianças aprendem com nossas atitudes cotidianas frente à vida - mais do que com o que pretendemos ensiná-las.

Para Heschel, o sublime não está em oposição à beleza e tampouco deve ser considerado como uma categoria estética. Amplia a ação do sublime como uma experiência além dos âmbitos acima descritos, quando diz que o sublime pode ser sentido nas coisas belas tanto quanto nos atos

\footnotetext{
${ }^{69}$ Cf. Ibid., p.138.

${ }^{70}$ Cf. Abraham Joshua HESCHEL, Deus em busca do Homem, op. cit., p. 56-57.
} 
de bondade e na busca da verdade. A percepção da beleza pode ser o princípio da experiência do sublime. ${ }^{71}$ Heschel refere-se à interessante análise de Max Glank, nos seguintes termos:

O sentimento de admiração como origem da nascente inexaurível do desejo (da criança) pelo conhecimento. Leva a criança, de modo irresistível, a solucionar o mistério, e se em sua tentativa ela encontra um relacionamento casual, ela não se cansará de repetir a mesma experiência dez vezes, cem vezes, a fim de sentir as emoções da descoberta vezes sem conta. (...) A razão por que o adulto não se maravilha tanto não é devido ao fato de ter ele solucionado o enigma da vida, mas porque ele cresceu acostumando-se às leis que governam seu ambiente de vida. Mas o problema por que estas leis particulares e não outras permanecem, é para ele tão estranho e inexplicável como para uma criança. Aquele que não compreende esta situação interpreta erroneamente seu profundo significado, e aquele que encontrou um estágio onde ele não se maravilha tanto a respeito de coisa alguma, demonstra, pura e simplesmente, que perdeu a arte do raciocínio reflexivo. ${ }^{72}$

Heschel refere-se àquele amor que busca a Verdade. Amar ao próximo como a si mesmo significa um profundo empreendimento pessoal que nos demanda esforço e coragem da consciência em obter equilíbrio pelo confronto com aspectos sombrios da personalidade, o mal (a maledicência) que na maior parte das vezes, é ao outro atribuído. Para Heschel, tudo o que existe obedece a certa ordem como ser natural, entendendo que só o homem ocupa um status único e, como ser humano, freqüentemente, tem sempre que escolher qual caminho tomar. ${ }^{73}$ Deste modo, no entender do autor:

O homem está sempre diante da alternativa de escutar ou a Deus ou a serpente. É sempre mais fácil invejar o animal, adorar um totem e ser dominado por ele do que atender à Voz. Nossa existência oscila entre a animalidade e a divindade, entre o que é mais e o que é menos que a humanidade: abaixo está a evanescência, a futilidade e acima a porta aberta do tesouro divino onde depositamos a moeda da piedade e do espírito, os restos imortais de nossas vidas mortais. Estamos

\footnotetext{
${ }^{71}$ Cf. Ibid., p. 6o-61.

${ }^{72}$ Max GLANK apud Abraham Joshua HESCHEL, Deus em busca do Homem, op. cit., p. 67-68.

${ }^{73}$ Cf. Ibid., p. 215.
} 
146 | Veritas | Porto Alegre, v. 63, n. 1, jan-mar. 2018, p. 121-149

constantemente entre as mós da morte, mas somos também contemporâneos de Deus. ${ }^{74}$

Em seu livro Passion for Truth ${ }^{75}$, Heschel toma as figuras de dois grandes sábios da Torá, o Baal Schem Tov, ou Mestre do Bom Nome, o exemplo da misericórdia, e o Koszker Rebbe, o exemplo da ação da justiça, como forma de lidarmos com os impulsos egocêntricos da natureza humana. A principal atitude a ser tomada na busca de auto-conhecimento é exigir-se um trabalho constante de reflexão, questionar-se a respeito da finalidade de nossas intenções, e ter, como principal objetivo, o revelar-se a si mesmo.

É preciso tanto duvidar da natureza de nossas boas intenções quanto das autojustificativas, pois estas nos servem como um meio de não assumir atitudes eticamente desprezíveis, como também não nos responsabilizamos pelos jogos de poder que engendramos. Portanto, no confronto interno, é preciso ter coragem suficiente para admitir a desilusão com a própria auto-imagem, o que necessariamente implica experimentar o sofrimento do qual muitas vezes, preferimos nos esquivar. Podemos evoluir como seres humanos e aprender a amar somente a partir do esforço em reconhecer as características negativas que em nossa alma habitam, como a inveja, o ódio e o orgulho. A busca da integridade para Heschel é inerente à consciência de que:

Honestidade, autenticidade, integridade sem amor podem levar à ruína dos outros, de si mesmo ou de ambos. Por outro lado, amor, fervor ou exaltação sozinha, pode seduzir a viver num Paraíso alucinado - o Inferno do sábio. É impossível encontrar a Verdade sem estar amando, e é impossível experimentar o amor sem ser verdadeiro, sem viver a Verdade. ${ }^{76}$

O milagre é a vida, ela própria é a fonte de onde jorra Luz inesgotável. Podemos atribuir sentidos ao sofrimento da alma em busca de respostas para conflitos de ordem existencial, numa postura humilde de aprendizado que oculta em si mesmo o sentido para o despertar da consciência espiritual. Nesse sentido, o equilíbrio dinâmico das

\footnotetext{
${ }^{74}$ Ibid., p. 218-219.

${ }^{75}$ Cf. Abraham Joshua HESCHEL, Passion for Truth. New York: Farrar, Straus and Giroux, 1973.

${ }^{76}$ Abraham Joshua HESCHEL, Passion for Truth, op. cit., p. 45 (Tradução nossa)
} 
polaridades é a expressão da beleza, como a boa medida dos sentimentos, e da alegria que nasce da compreensão e da gratidão por saber-se existir. A alegria é um estado que pode ser compreendido como o resultado desse trabalho da consciência e a sensibilização para percepção do evento ou da série de eventos, o insondável, e que acabam por se transformar na consciência.

Entendemos que Heschel nos propõe resgatar o olhar da criança e o reaprendizado que é o espanto frente ao deslumbramento da criação na trilha do maravilhoso mistério e no ato divino, que a tudo envolve desde a primeira inspiração. A delicadeza da expressão dos sentimentos, na linguagem do autor, é capaz de nos conduzir a percepção de matizes e nuances da expressão de nosso mundo emocional. Diz apropriadamente que "o tema do lirismo bíblico não é o encanto ou a beleza da natureza; é a grandeza e o aspecto sublime da natureza que a poesia bíblica tenta celebrar" ${ }^{77}$. Os milagres só acontecem àqueles que Nele crêem! Por isso, segundo Heschel:

O sublime para o judaísmo não é uma categoria estética. O sublime pode ser sentido nas coisas belas tanto como nos atos de bondade e na busca da verdade. A percepção da beleza pode ser o princípio da experiência do sublime. O sublime é aquilo que nós vemos e é quase incapaz de comunicar-se. É a saliente alusão às coisas com um significado maior do que elas próprias e pode ser sentido em cada grão de areia, em cada gota de água. Cada flor na primavera, cada floco de neve no inverno, podem elevar-nos a um sentimento do maravilhoso que é nossa manifestação do sublime. ${ }^{78}$

O sentimento do maravilhoso resulta de um estado de elevação ao qual o sublime nos remete. Para Heschel, "o sentido do sublime deve ser observado na raiz das atividades criativas do homem na arte, pensamento e nobreza de vida"79. É a intuição, como um olhar sobre a vida revelada, que oculta em si sua magnitude, a sensibilidade àquilo que só podemos aludir à Presença. Heschel, continuando sua análise sobre o conceito de sublime, faz uma crítica a Edmund Burke (1729-1797) e a Immanuel Kant

\footnotetext{
${ }^{77}$ Abraham Joshua HESCHEL, Deus em busca do Homem, op. cit., p. 57.

${ }^{78}$ Ibid., p. 6o-61.

${ }^{79}$ Ibid., p. 61.
} 
$(1724-1804)^{80}$ que tratam o conceito contrastando-o com a beleza. Para o autor, a forma como estes pensadores descrevem o significado e a percepção do sentimento de sublime não é muito adequada, pois este não está em oposição à beleza, não pode nem mesmo ser considerado uma categoria estética e não está necessariamente relacionado com o vasto e o esmagador.

O autor diz que, diferentemente, para o homem bíblico, o sublime é apenas um caminho no qual as coisas reagem à presença de Deus. Não tem uma qualidade de significado próprio nem tampouco compreende um aspecto essencial da realidade, mas existe para algo além de si mesmo. “... é um acontecimento, um ato de Deus, uma maravilha. O que parece ser pedra é um drama; o que parece ser natural é extraordinário. Não há fatos sublimes; há unicamente atos divinos" ${ }^{81}$. Em contraste, a reação do piedoso que sente o sublime é ser arrebatado por sua ânsia de exaltar e de louvar o Criador do mundo. E, segundo o autor, diante dos sinais de ameaça, o homem bíblico diz: "Ainda que eu andasse pelo vale da sombra da morte, não temeria mal algum, porque tu estás comigo (Sl 23,4)" ${ }^{82}$.

A reação aos objetos sublimes, céu, estrelas, tem um mistério em comum e depende da nossa capacidade de mantermos a percepção sensível à experiência da religiosidade, o que dá ensejo a cultivar continuamente o Deus vivo. Heschel concorda que isso acontece porque a reação aos objetos sublimes não é simplesmente perplexidade terrificante ou a estupefação da mente e dos sentidos, mas, sim, maravilha e pasmo. ${ }^{83}$

\section{Referências}

Abraham Joshua HESCHEL apud Alexandre LEONE, A imagem divina e o pó da terra. São Paulo: Humanitas-FFLCH/USP-FAPESP, 2002.

Abraham Joshua HESCHEL, Deus em busca do Homem. São Paulo: Paulinas, 1975.

Abraham Joshua HESCHEL, O homem não está só. São Paulo: Paulinas, 1974.

\footnotetext{
${ }^{80}$ Heschel baseia sua análise em Edmund BURKE, A Philosophical Inquiry into the Origin of our Ideas of the Sublime and the Beautiful, e Immanuel KANT, Krititik der Urteilskraft.

${ }^{81}$ Abraham Joshua HESCHEL, Deus em busca do Homem, op. cit., p. 62.

${ }^{82}$ Ibid., p.63.

${ }^{83}$ Cf. Ibid., p. 53-63.
} 
M. Hazan; L. Pondé - A Presença de Deus no Ser Humano segundo Heschel | 149

Abraham Joshua HESCHEL, O último dos profetas. São Paulo: Manole, 2002.

Alexandre LEONE, A imagem divina e o pó da terra. São Paulo: Humanitas-FFLCH/USPFAPESP, 2002.

\section{Endereço postal}

Pontifícia Universidade Católica de São Paulo, Departamento de Teologia, Programa de Estudos Pós-Graduados em Ciências da Religião.

Rua Ministro de Godói, $9694^{\circ}$ andar

Perdizes, Sao Paulo, SP - Brasil

Data de recebimento: 17/01/2018

Data de aceite: 13/03/2018 